\title{
Criterion of Construction Process Investigation with a Vision of Sustainable Construction (in Iran with a Regard to UK)
}

\author{
Mahsa Rezazadeh, Milad Rezazadeh , Zahra Balador, and Sara Shabahang
}

\begin{abstract}
Considering the raise in energy and material costs, the importance of preserving the existing raw materials, and also the need of accommodation and reaching sustainable construction, this paper explores the methods of optimization of energy and material in the construction process.

Studying and comparing construction process and energy use in Iran with developed countries ( which is England in this study) and reaching methods which causes a great difference in use, implementation methods and construction process and also recognizing the problems and proposing solutions to solve these problems can help us reach a sustainable construction.
\end{abstract}

Index Terms - Construction problems, energy, waste of material, strategy, sustainable construction.

\section{INTRODUCTION}

The need to develop accommodation is inevitable because of the increase in young generation population and family numbers. This rapid growth has involved building experts and Non-specialists to solve the problem. But non standard construction has caused negative effects. Some of the consequences are because of lack of careful monitoring on the implementation of the regulations due to the large quantity of buildings, and lack of durability and sustainability of materials. Using improper material and inefficient methods which are aimed at decreasing the costs are the main reasons of many of these challenges.

Comparing construction process in Iran with that of a developed country and recognizing its weak points and proposing strategies to solve the problems can play a great role in reaching sustainable construction which is one of the factors of sustainable developments.

The present research was done in seven main fields which are as follows: material, work force, construction methods, master, energy, problems during function, building identification document. (Fig. 1)

Manuscript received May 7, 2013; revised July 10, 2013.

Mahsa Rezazadeh is with university of Mashhad, Iran (e-mail: archbanoo@gmail.com).

Milad Rezazadeh is with Architecture Department, "Architecture Technology", University of Tehran, Iran ( e-mail: m.rezazade@ut.ac.ir).

Z. Balador is with Architecture Department, "Architecture and Energy", University of Tehran, Iran ( e-mail: z.balador@yahoo.com).

S. Shabahang is with Azad university of Mashhad, Iran (e-mail: sarash_59@yahoo.com).

\section{MATERIAL}

\section{A. Material Quality}

The way to choose the building materials has a great effect on the project final quality. The materials used in construction are divided into two groups: industrial (factory materials and pre fabricated materials) and traditional. In Iran; although there are some standards for choosing materials, there is no guarantee to obey these rules. Moreover, lack of accommodation and poor families' housing requirements have lead to prioritize house quantity over quality. In fact, because of trying to reduce costs, not observing the process and buyers' lack of knowledge this issue has been abused. On the other hand, "In England in case of using materials with low quality and improper methods, building insurance will face difficulties and cost a lot and also building ID (which defines building existence and includes the related authority's idea regarding the building main construction factors) will be affected and influences the house selling price"[1]. Therefore, in England it is tried to use high quality materials and cheating in this area is avoided.

Discussing the use low quality materials, it should be mentioned that national standards have set a desired quality but a comprehensive definition has not been yet defined. In England, industrial materials play a greater role in construction industry. While in Iran, as a result of low prices and lack of knowledge in construction, traditional materials play an important role. Considering the mentioned issues, it is better to use standard material. Factory materials normally have a better quality control and have less material waste. Better implementation and higher efficiency are the advantages of these materials. It should be considered that these construction methods cost more than regular methods but in function and destruction stages they produce less waste and also cost less because of ease of dismantling and disassembly.

\section{B. Recycling and Waste of Materials}

Recycling includes a process in which unwanted materials are changed into new products and this avoids wasting the potential of unwanted materials. In England while destroying a building, building wastes are separated carefully to be recycled.

The regular way of building in Iran is to gather materials in different parts of the building which makes it impractical to separate building parts and recycle them.

Regarding the fact that in Iran buildings lifetime is one fourth of England in its ideal form waste of material in Iran is 
four times of England.

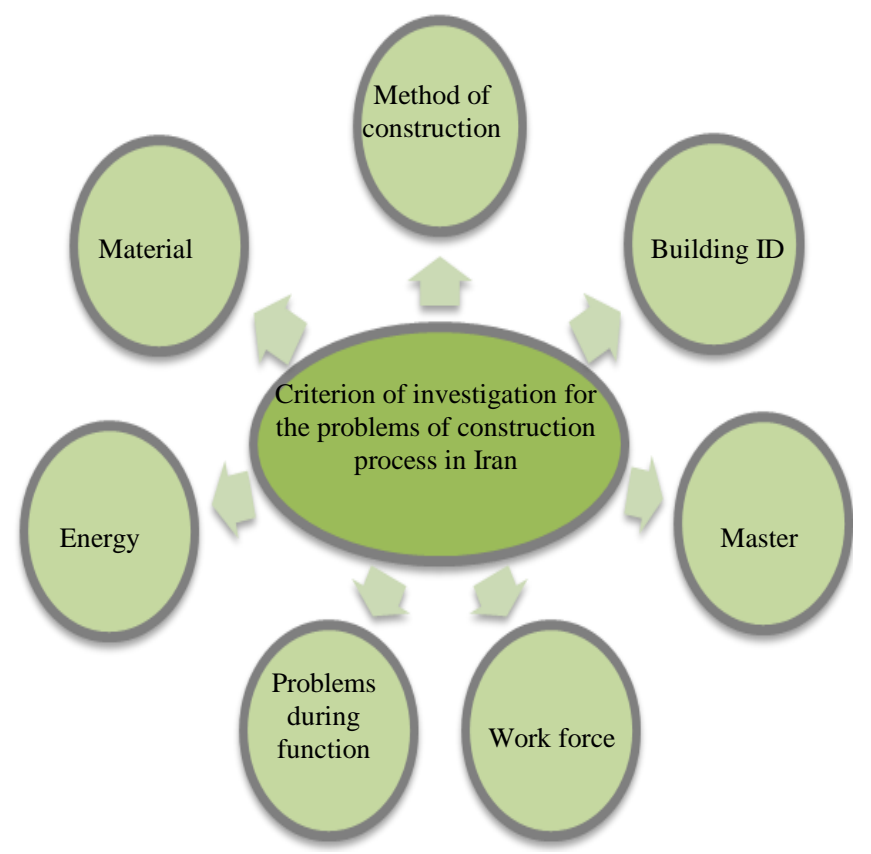

Fig. 1. Criterion of investigations for the problems of the construction process in Iran

"In England, the great tax of storing encourages builders to produce the least possible trash and to reuse destroyed material. Moreover in case of reusing materials, their final tax will be reduced [1]."

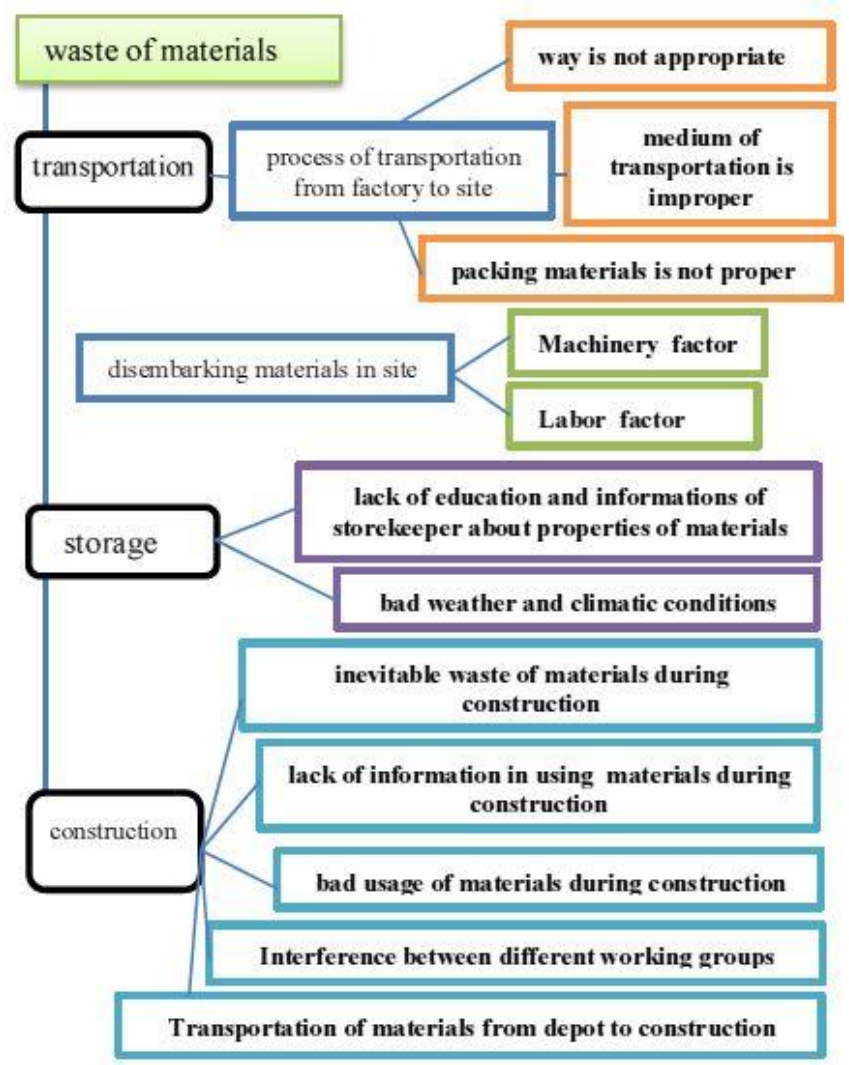

Fig. 2. Important factors of wasting materials in Iran.

\section{1) Difficulties of recycling in Iran}

- Not paying attention to the importance of material recycling.

- Not preserving the existing building regarding the benefit of destroying and reconstructing the buildings.

- traditional building methods.

- Less useful lifetime of buildings in Iran.

- Lack of proper governmental policies to force or encourage contractors and users.

Some suggestions in accordance with construction process in England to solve the problem of construction waste[1]:

- Destruction should be performed by experienced groups and those aware of optimized methods of destruction and waste separation.

- Building codes should obligate observers to control destruction and waste separation.

Generally, applying proper encouraging policies, we should try to decrease construction waste and increase its recycling rate.

\section{2) Material waste in Iran}

Material waste in Iran happens in three levels:
a) Transportation
b) Storage
c) construction

Factors affecting material waste are presented in the following diagram. (Fig. 2)

\section{WORK FORCE}

Factors such as design quality, material selection, construction quality and ... affect building quality. Quality of each of these factors depends on labors and contractors' proficiency. Active work force in construction industry can be divided into four groups:

1) Engineers and experts who mainly possess academic education

2) Technicians who are mediators between engineers and workers

3) Experienced workers

4) Simple Workers

In England there are especial trainings for these groups and usually people who have not been trained are not employed.

All groups have defined wages; therefore they try to be the best in their group. But in Iran workers are less committed to their job and often people who are less educated work in this field. These issues lead to low quality and non-standard construction.

Iran universities educational system is theoretical-based which is normally different from site realities. As a result, many engineers while being aware of the general knowledge are not capable of analyzing the problems in the construction site and finding proper solutions due to the lack of experience.

On the other hand, construction sites lack technicians. Based on data obtained from field studies, building officials Observe the project just a few times and at the end of each phase and do not observe the whole process. Therefore it is vital to have experts who are aware of modern techniques and observe the process regularly. Moreover, appointing technicians in sites can reduce material waste to a large degree as a result of accurate material estimation. For example, a false estimation of the needed cement has no way back. Also a technician can guarantee a good implementation of all details. But at the present time in Iran most projects are done by 
experienced and simple workers.

Experienced workers mainly work as contractors such as reinforcing bar worker, welding worker, stone worker ... The problem in this regard is the inability to assess their expertise. masters or developers choose these contractors on the basis of their references. On the other hand, these workers have lots of experience but are not aware of new technologies and techniques and are resistant to these methods.

"In England, specialized companies are obliged to train their staff and guarantee their work quality with attaching a certificate to the building ID [2]."

Training builders is essential and should be considered in order to improve and speed up the project. But the important issue is that if this training takes a long time, it would be inefficient due to change of construction methods, standards and building technology.

In Iran, different regulations such as vocational trainings are set but to be welcomed by public, there should be an accurate plan and the obstacles against employing trained people should be recognized and erased.

Now another problem of construction industry is appointing unqualified workers in the construction process. This kind of employment is not standard. These workers are mainly in the lower level than technicians and it leads to buildings poor quality, unsafety of occupants, loss of national sources and increase of low-quality construction.

One of the other problems of construction in Iran is a weak design which is caused by rapid growth of engineering companies and their lack of experience. In England, in order to attract customers' satisfaction regarding work quality, employers avoid working with inexperienced people and they employ consultants and experts. Young engineers are often employed by experienced companies and they rarely start their own business.

In Iran, due to inability to buy proper materials many people and masters are content with low quality material and design, and construction.

Moreover, benefits of house construction have attracted unprofessional people.

\section{Construction Method}

\section{A. Industrial}

\section{B. Traditional}

\section{Construction Management}

At the present, the main method of construction in Iran is traditional method which is uncontrollable regarding its quality and it is very difficult to improve its technical specifications. Therefore it has a short average lifetime. "Traditional methods of construction are neither optimized concerning its materials and structural elements production. So shifting to industrial method is inevitable.

Also, because of lack of possibility of proper management and accurate planning, final price of traditional methods is high with regarding final result and generally it is a time consuming process."[3]

"Industrialization share is now 40\% in Iran"[4] which has increased well but it is caused by Mehr Construction Project which has raised industrial statistics. The one in charge of Iran industrialization is government and the target group is the low class of the society which has caused the contractors to reduce the quality of the project to make it cheaper. On the other hand, government change of policies reduces the industrialization percentage to the previous amount of 2-3\% while this percentage is much more in England and it is not limited to cheap or government sector. (For example, in London houses look traditional but their design and construction method is modern and industrial while in Iran buildings look modern but are constructed traditionally.)

Transferring knowledge of industrial construction to workers improves industrialization in construction and reduces the final price without decreasing the quality.

\section{Construction Management}

At the beginning of a project, one of the most important strategic decisions is its construction method. Nowadays, various methods are used in constructing projects worldwide. Each of them has its own advantages. One of these methods is the method of construction management that from its beginnings in the $60 \mathrm{~s}$ in England and other European countries was welcomed by the public and private sectors and, experiences suggest that this approach has been very successful [5].

Construction Management includes knowledge of planning, coordination and project control from the beginning to the end. The construction management is wise utilization of resources (human resources, machinery, materials and capital) to efficiently and effectively build a constructive project to meet most demands of the master.

In our country according to fix the shortcomings of the traditional three-factor, the idea of this method was introduced from the mid 70's, and gradually its criteria was notified to be used in governmental projects. Now after a few years, the results show that this approach has not been successful as expected. Considering field studies, some challenges have been observed in the construction management compared with UK which will be referred to later.

In a project, to achieve maximum results, both qualitative and quantitative considerations must be considered together by the construction manager. In the quantitative considerations we can refer to: specifying the stages of project, the number of personnel, equipment capacity, and layout of the site.... Also items which are qualitative and not countable such as: staff motivation, how to communicate with different groups working on the project, contracts and legal responsibilities are important. One of the differences between Iran and UK managing construction sites is lack of attention to qualitative aspects of management.

"Following the schedule, not deviating from the budget and observing employer's quality standards, are three essential principles for success of a construction project. In other words, the main construction management challenge is resource allocation in terms of allocated time and budget. This challenge exists in all construction projects due to the nature of construction industry."[6]

Facing this challenge requires being skillful in various fields. A construction manager must have merit, competence 
and sufficient ability in terms of quantity and quality which have been already explained. Outstanding academic ability alone is not sufficient for a successful construction manager, he should also be capable on the other aspects of the project such as: laws of contracts, communication management, how to deal with the problems and setting the priority of the goals. It is important to note that in Iran while selecting a construction manager, these aspects are not considered completely.

\section{MASTER}

Now a days housing development in our country often has three forms:

1) Mass construction

2) Apartment or villa built by the owner, in specific urban areas

3) Unauthorized housing that are often built in the outskirt

In Iran, the majority of masters are private companies and usually one or more masters for each piece of land refer to a real or legal entity and order a design or to construct. For example in an alley about 20 or even 30 contracts of designing or construction may be signed. However, in some cases Private or governmental companies attempt to mass construction, but this takes place in special circumstances. Generally, government sponsor mass construction in the housing sector, which are mostly built for a specific aim.

But in England usually, a private company builds a house and a company in specific land or even in a city block purchase or rent the land, the next step is to build houses on large scale. This helps the use of prefabricated construction and industrialization in the construction process and also reduces the overall cost.

Users buy houses from companies (often private), so competition in quality and price, comes in the housing market and due to high number of houses, they are sold with low profits (without intermediaries).

Construction cost of a separate house in England is high and often wealthy employers do so.

\section{ENERGY}

Energy used in the construction process is divided into two categories:

1) The energy used in the construction process

2) The energy consumed during function of the building

Basic ways of energy consumption during construction:

a) Energy used for the extraction and processing of raw materials

b) Energy required for transportation of materials and equipment to the site

c) Energy required during the construction process

Energy used for the extraction and processing of raw materials and energy required for transportation of materials and equipment to the site depends on the infrastructure of a country. Mining problems and no optimization of raw material processing machines are some of the impressive factors in the energy consumption [7].

But about the issue of energy consumption during the construction process we can say that the time period of construction in our country is more than UK and on the other hand the efficiency of energy consumer equipment and construction process in our country is typically lower than standard.

Considering the following points and an attempt to overcome these points, can get closer to the optimization of the energy consumption.

Traditional construction results in higher energy consumption and also, not using new, prefabricated and industrial materials, which are manufactured as series and energy and cost efficiently, are some of the effective factors in increasing energy consumption during the construction process [8].

Small modules of construction (e.g., bricks) and using linear, planar and especially solid modules can reduce the time and energy consumed in the construction process.

Lack of restrictive regulations and incentives on energy consumption during construction.

Lack of knowledge of the workforce and training in energy efficiency

Lack of workers' knowledge regarding proper use of energy consuming equipment.( such as unprofessional welding _ by excessive welding, not only energy is consumed too much but also consumed steel will treat fragile and brittle against forces. )

Energy consumption during using the building depends on two factors: Special preparations during construction (such as proper insulation, and ...) and also the culture of the occupants. However, government policies particularly on energy prices, affects the amount of consumption. Most of the energy in the housing sector, is spent on heating houses (This part in Iran is divided between heating and cooling the house) consequently, proper insulation and good windows are the main solutions for reducing energy consumption in the buildings [9].

\section{POST-OCCUPANCY ISSUES}

Three cases have been studied regarding the use of the house:

1) Possibility of post-occupancy Access and maintenance

2) Building insurance

3) Connection between builder and user

\section{A. Post-Occupancy Access and Maintenance}

In Iran access possibility to the vital arteries (Utilities, etc.) at the time of use seldom has been considered. Lack of access to utilities for repair or replacement and also lack of possibility to make minor changes without fail at the time of operation, are some of the problems which users have to deal with. During the initial design and construction, utilities are usually implemented hidden and paying attention to the necessity of flexibility of some parts of the building for repairs, is neglected. While in England, installing valves for Inspection and repair is one of the requirements to get the certificate of occupancy and from early stages of the design, contractors pay attention to this issue which cause these problems being solved through architectural design. Possibility of Opening and relocating Internal or external walls adjacent with the ducts of utilities, is another approach that is practical for solving this problem. 


\section{B. Building Insurance}

These days construction industry plays a specific role in the process of development of progressive communities. According to the Massive investment and its impact on the national economy, every country tries to increase the quality and lifetime of the building, besides to decrease the cost and time of construction by using modern technologies and methods. For example in England, to achieving these goals, besides extensive and long-term planning, always they have tried to improve the control system by taking advantage of the technical and engineering potential of the private sector. One of these methods is a compulsory plan to submit quality assurance in the form of a comprehensive building insurance which now, has dedicated an important place to itself in the construction industry and in the enhancement of the quality. Considering this issue, Insurance companies with regard to their essence which is to bear less risk and more profit, to avoid paying hefty compensation, by providing facilities and taking advantage of specialists and technicians, practically as an independent factor to control quality of construction besides the other regulatory factors along with continuous control, they prevent any shortcomings and failures. In these circumstances, contractor and master have to build their building according to the standards accepted by insurance companies which is confirmed by the other regulatory factors, so they can catch a quality assurance in the form of a comprehensive building insurance as a permit and give it to the consumers. There is no doubt this system will benefit both the master and the interests of the consumer. Because the master can sell the building with higher prices by having a comprehensive building insurance as a quality assurance which represents that it has a good technical quality. And the consumer, who puts its own property at risk, can accommodate in these places by paying more money confidently and without unpredictable costs. Now in our country, because of lack of such a system a consumer who pays all the money he has, practically takes a risk. Because just after delivery and issuance of the building documents, he will be more involved and responsible against accidents and for different compensations and it is not possible for him to prosecute the master and contractor[10]. Perhaps in most situations basically, the contractor either has gone abroad or is lost! Obviously, this approach is irrational and unfair. Because someone who has had no role in construction process, in addition to endangering his capital, he should be responsible for early corrosion in an unusual manner and its unpredictable human and financial consequences. In such circumstances, lack of quality assurance system has caused masters not to fulfill their legal and ethical responsibilities in order to profit more and without minimum quality, simply with hypocrisy and demagoguery, they try to sell their building. It is obvious that it has caused the average useful life of the building to decline to less than 20 years and can cause adverse effects on the economy of the country. Unfortunately, in recent years, despite extensive efforts in order to enhance the quality of the construction industry in the country, there is no comprehensive building insurance despite good conditions and regulatory approvals issued by the highest authorities of the country; this has been remained in the halo of ambiguity.

\section{Connection between Contractor and Users}

In this regard, there is a problem that usually in the design and construction stage, contractors do not have any contact with the users of the building, so after completion and delivery to final user there is not any possibility to meet users' demands. If it is possible it is better whether the designer become informed about the demands of the user directly at the time of designing or the building is designed flexibly to meet the demands of future occupants. Using portable walls or designing a flexible plan can be the solution.

\section{BUILDING ID}

Providing building ID is in order to make a proof of the level of qualification standard and acceptability of all phases of construction and materials and equipments. At the present time, ID only includes the quantity data (area, number of floors, type of structure...) and the proprietor cannot judge the real specifications of the building by these profile appearance, therefore the necessity of preparation of this quality documentation of building that presents identity of the building for the owner or the purchaser, is apparent.

The quality documentation of building informs us in three levels: 1- structure of the building 2- utilities 3-finishing

In each level building is classified into two parts (quality of materials and equipments- quality of construction) (Fig. 3).

It is obvious that, for achieving an accurate classification, proper standards and principles are needed to judge building and also, necessary control and monitoring should be done in order to make this document valuable not only to get the certificate of occupancy but also to help us to choose correctly, that is possible if related organizations cooperate. Moreover preparation of ID is a factor which will facilitate getting the building insurance when it starts to function and this will solve many problems such as possible damages.

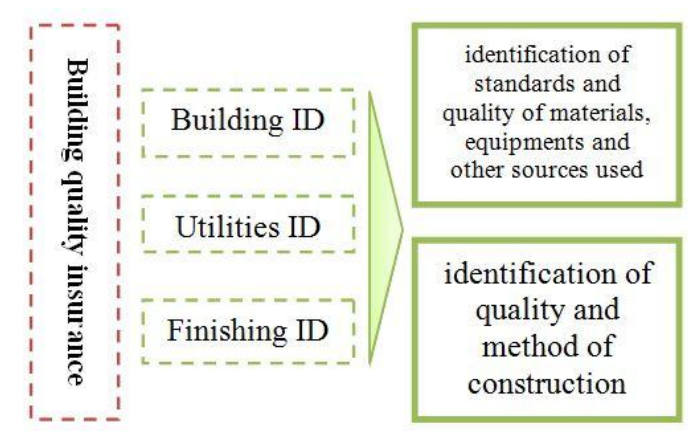

Fig. 3. Building quality insurance.

\section{CONCLUSION}

In concluding the discussion, it is necessary to note that the approaches presented in each section requires appropriate legislation and providing necessary conditions by government and also needs public desire achieve higher quality in construction sector.

However, the need for housing has partially spoiled the ability of deciding especially of low-income and poor people on the selection of better quality (especially in the housing sector). 
One of the proposed solutions in this field is building ID, which not only gives accurate statistics on the status of construction in the country to the authorities, but also there is a possibility at the time of selecting by the purchaser to assess the real specifications of the building, encouraging contractors to construct buildings according to strict and accurate engineering principles. However it is necessary to note that lack of precise monitoring on issuing this ID will cause committing fraud in the preparation and making that worthless.

Another factor that improves the construction industry and enhances the quality of built structures, is building insurance which makes the possibility of monitoring simpler, because the company which will provide the building insurance, firstly must make a detailed study on the building then denote the payable amount to insure the building and this amount will decrease if construction is built in accordance with principles and quality standards, because it is less likely to fail, and if it is not carefully studied and monitored, the insurance company will eventually lose, so it is necessary to be careful.

Training the workers and making engineers familiar with the construction techniques will be effective in achieving high quality buildings.

Overall, as it was mentioned, we should extend the use of modern materials and technologies to achieve sustainable construction by informing and making conditions appropriate.

\section{REFERENCES}

[1] DAVIS LOMGDON LLP, Spon's Architect's and Builder's Price $B o o k$, one hundred and thirty-fifth ed. Oxon,U.K.: spon press, ch. 1, pp. 35-53, 2010.

[2] UK Commission for Employment and Skills, Sector Skills Insight S: Construction, Evidence Report 50, July 2012.

[3] Housing research organization, Journal of Modern Building Technolog, fifth ed. 2009.

[4] Website of Management of Iran construction projects company. (2012). [Online]. Available: http:/www.inn.ir (Mapsa).

[5] M. P. Jalal and E. F. Kar, "Review the Terms of management method in the construction of the country," presented at First International Conference on Project Management, Tehran, Iran, 2004.

[6] M. M. Mahmoudi, Housing Development Compatible with Sustainable Development, Tehran University Press, , 1388, $1^{\text {st }}$ ed. ch. 1 , pp. 7,ch. 3, pp. 124-145.
[7] M. J. Saghafi and A. S. Samiei, "Environment relationship with incompatible adjacent materials and energy efficiency in buildings," Architecture \& Urbanism, vol. 4, pp. 22 -30, 2010.

[8] A. Druckman and T. Jackson, "Household energy consumption in the UK: A highly geographically and socio-economically disaggregated model," Energy Policy,vol. 36, pp. 3177-3192, 2008.

[9] N. Hamzan and R. Gilroy, "The challenge to UK energy policy: An ageing population perspective on energy saving measures and consumption," Energy Policy, vol. 39, pp. 782-789, 2011.

[10] M. M. Mahmoudi, "Analytical report on study of the general conditions of creating technical and professional liability insurance (architects, surveyors and supervisors)," Rah Shahr, 1375.

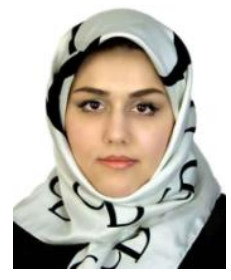

Mahsa Rezazadeh was born in Mashhad, Iran. She obtained the bachelor of architecture and M.Sc. degree in Architectural Engineering in 2006 from department of architectural engineering, faculty of Engineering, Azad University of Mashhad. Her major field is flexible architecture and building technology. She is an architect consultant in faculty of engineering, Azad University, she made many project in the university and her own.

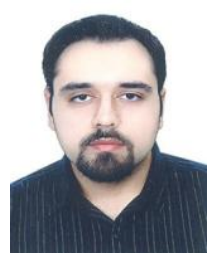

Milad Rezazadeh was born in Mashhad, Iran. He received a B.S. degree in Architecture from Azad University of Mashhad, Iran in 2010. he is a graduate student in "Architecture Technology" at Architecture Department, University of Tehran, Iran. His research works focus on tall building and seismic design, material recycling and sustainable architecture.

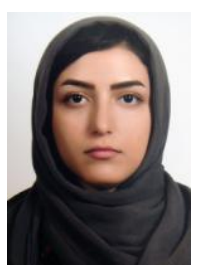

Zahra Balador received a B.S. degree in Architecture from Ferdowsi University of mashhad, Iran in 2010 She is a graduate student at Architecture Department, in "Architecture \&Energy", University of Tehran, Iran. Her research works focus on sustainable architecture and biomimicry strategies in architecture.

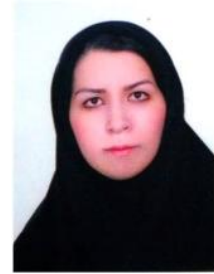

Sara Shabahang was born in Mashhad, Iran. She obtained the bachelor of architecture and M.Sc. degree in Architectural Engineering in 2006 from department of architectural engineering, faculty of Engineering, Azad University of Mashhad. Her major field is sustainable architecture. She is an architect consultant in faculty of engineering, Azad University. She made many project in the university and her own. 